\title{
Diffusion-Ordered NMR Spectroscopy of Poly([ethylene-co-vinyl acetate]-graft-vinyl chloride) in Solution
}

\author{
Sangdoo Ahn," Eun-Hee Kim, and Chulhyun Lee \\ Department of Chemistry, Chtmg-Ang Lnwersity, Seoul 156-756, Korea. "E-mail: sangdooacau.ackr \\ ${ }^{+}$Hagnatic Resonance Team, Korea Basic Science Institute, Daejeon 305-333, Korea \\ Received October 20, 2004
}

Key Words : Graft copolymer. Diffusion. PFG. DOSY

Two-dimensional nuclear magnetic resonance (2D-NMR) spectroscopy employed pulsed-field gradient (PFG) techniques has become one of the most important tools for studying the structure and dynamics of all types of chemical and biological conpounds in solution states. Very recently, a newly developed 2D technique, diffusion-ordered 2D-NMR spectroscopy (DOSY) has generated significant interest because it produces NMR spectra of mixtures to be resolved on the basis of the size and shape of components present in the mixture. ${ }^{1.2}$ As the gradient strength increases. in DOSY experiments, signals decay exponentially according to the translational diffusion coefficients of individual molecules which largely depend on physical parameters like temperature, solvent viscosity. and size and shape of the molecule. Effective data inversions of the decay curves depending on the gradient strength produce a two-dimensional NMR spectrum that shows correlations between chemical shifts in the directly observed dimension and the calculated diffusion coefficients in the indirectly observed dimension. ${ }^{1}$ There have been many reports suggesting its potential applications because this $2 \mathrm{D}$ experiment permits a noninvasive chromatographic separation of conponents in a mixture solution without need to any preliminary physical separation. ${ }^{3.11} \mathrm{By}$ coupling of DOSY to the other conventional NMR techniques. such as COSY-DOSY, INEPT-DOSY. HMQCDOSY. HMBC-DOSY. and etc. all structural units in a mixture can be examined simultaneously. ${ }^{1,12}$ DOSY NMR can also be used as a powerful tool to distinguish between the complexed and noncomplexed forms in a mixture of host and gnest compounds due to the differences in their diffusion coefficients reflecting the changes in their size and mass accompanied by complex formation. ${ }^{6,13-15}$

NMR spectroscopy is also an invaluable tool for the quantitative and qualitative analysis of polymers. ${ }^{16}$ Differing from relatively well resolved ${ }^{13} \mathrm{C}$ NMR spectra of polymer solutions. proton NMR spectra are usually not well resolved due to the fast relaxation and molecular weight distributions of the polymers. This frequently makes it quite difficult to perform complete peak assiguments in polymer mixture samples by ${ }^{1} \mathrm{H}$ NMR spectroscopy. DOSY NMR has been introduced to solve such kinds of problems in polymer mixture systems (e.g. polymer-polymer mixtures and polymer-additives mixtures). ${ }^{8,10,17,18}$ In this work, a new potential of the 2D-DOSY technique for the analysis of graft copolymer solutions has been investigated by comparing the diffusional behavior of the target copolymer with the mixture of constituent polymers. By conventional ${ }^{\mathrm{H}} \mathrm{H}$ NMR spectroscopy, some graft copolymers are not distinguished from the mixtures of their constituent polymers.

\section{Experimental Section}

A commercial graft copolymer ethylene-vinyl acetategraft-vinyl chloride (EVA-g-VC, $M_{\mathrm{w}}=138000, M_{\mathrm{w}} / M_{\mathrm{n}}=$ 3.2) manufactured by Shin Dai-Ichi Vinyl Corporation (Japan) containing $55 \mathrm{wt} \%$ of EVA has been used. This polymer has hardness equivalent to $\sim 50$ part per hundred resins (phr) plasticizer can be obtained. and was synthesized by grafting vinyl chloride onto EVA copolymer. For a mixture sample, a commercial PVC (LG Chem. Korea, $M_{w}$ $=83000 . M_{\mathrm{w}} / M_{\mathrm{n}}=2.1$ ) polymer and EVA copolymer (Sumitomo. Japan. $M_{\mathrm{w}}=49000, M_{\mathrm{w}} / M_{\mathrm{n}}=3.4$ ) were used. A soft PVC eraser with $\sim 40$ plur dioctylphthalate (DOP) as a plasticizer was used for a control experiment to separate the additive signals from the PVC peaks. Solutions of polymer mixture (PVC : EVA $=45: 55 \mathrm{wt} \%$ ) and graft copolymer in tetrachloroethane- $d_{z}$ containing $6 \mathrm{mg}$ of samples in $1 \mathrm{~mL}$ of solvents were prepared and were heated to $373 \mathrm{~K}$ for a day. The control solution was prepared by dissolving $20 \mathrm{mg}$ of eraser sample (PVC with DOP) in $1 \mathrm{~mL}$ tetralyd drofuran- $d_{q}$.

All NMR experiments were performed at $298 \mathrm{~K}$ on a Bruker Avance 600 spectrometer equipped with a Bruker $5 \mathrm{~mm}$ micro-imaging PFG probe and a strong gradient amplifier, which provides a $z$-direction gradient strength of up to $200 \mathrm{G} / \mathrm{cm}$. The temperature was maintained constant within $\pm 0.1{ }^{\circ} \mathrm{C}$ by means of the BVT-2000 unit. All DOSY experiments were performed using the bipolar pulse longitudinal eddy current delay pulse sequence (BPPLED). ${ }^{1,19}$ The spoil gradients were also applied at the diffusion period and the eddy current delay. Typically, a value of $0.5-1 \mathrm{~ms}$ was used for the gradient duration $(\delta), 100-120 \mathrm{~ms}$ for the diffusion time $(\Delta)$. and the gradient strength $(\mathrm{g})$ was varied from $4 \mathrm{G} / \mathrm{cm}$ to $100-180 \mathrm{G} / \mathrm{cm}$ in $32-128$ steps. Each parameter was chosen to obtain $\sim 95 \%$ signal attenuation for the slowest diffusion species at the last step experiment. The pulse repetition delay (including acquisition time) between each scan was larger than $10 \mathrm{~s}$. Data acquisition and analysis were performed using the Bruker xwinumur software (version 
3.5). The DOSY processing program as implemented in the xwinnmr was used to calculate the diffusion coefficients and to create two-dimensional spectra with .V.MR chemical shifts along one dimension and the calculated diffusion coefficients along the other.

\section{Results and Discussion}

Graft copolymerization has been used as a very important teclnigue for modifying the chemical and physical properties of polymers to meet specialized industrial needs. In general, the fonnation of the graft copolymer can be confirmed with NMR, IR spectroscopy, and sizc-exclusion chromatography. In . VMR spectroscopy, however, frequently it is very difficult to confinm the grafting due to the similarity of the VMR spectra with those of the polymer blends. In view point of this, 2D-DOSY N.MR could be a valuable and potential technique to distinguish between graft copolymers and the polymer blends of their constituents since the translational diffusion coefficients reflect the changes in the shape and/or size of polymers.

In DOSY experiments using the BPPI.ED pulse sequence, the signal intensity is generally given as ${ }^{1.19}$

$$
\left.I(q)-J_{(1)} \exp \mid-D q^{2}(\Delta-\delta 3-\tau / 2)\right]
$$

where, $I_{0}$ is the intensity of the signal in the absence of the gradient, $D$ is the translational diffusion coeflicient, $\tau$ is the time belween bipolar gradients, and $q \gamma g \delta$ is the effective gradient where $\gamma$ is the gyromagnetic ratio of the observed nucleus, $g$ and $\delta$ are the amplitude and duration of the gradient pulses, respectively. By use of z-gradient, molccules can be spatially labeled, i.e. marked depending of their position in the sample tube, and if they move during the diffusion time $(\Delta)$ a second gradient is used to decode their new position. The receiver integrates over the whole sample volume and the result is an intensity attenuation of NMR signal depending on the diffusion coefficients of molecules in the sample as described in Eq. (1). A good and detailed review about diffusion and DOSY experiments can be found in elsewhere.'

Figure 1(a) shows the 2D-DOSY spectrum (diffusion coefficient vs. 'H chemical shift) of the plasticized PVC sample (eraser) will the single-pulse ${ }^{1} H$.VMR spectrum drawn at the top of the DOSY contour plot. A typical diffusion decay curve for a DOP proton signal by varying the gradient strenglh is also shown in Figure 1(b). Since translational diffusion coefficients of all protons belonging to a single molecule also become identical, .VMR signals from each component in a mixlure appear parallel to the $x$ axis $\left(F_{2}\right)$ and are separated by each component on y-axis $\left(\mathrm{F}_{1}\right)$. Therefore, the results are similar to chromatographic separation. As shown in Figure I(a), it is clear that the DOP and the solvent (THF) exhibited much larger diffusion coefficients than the PVC, as might be easily expected on the basis of their large diflerences in molecular sizes compared with the polymer. This implies that the N.MR (a)

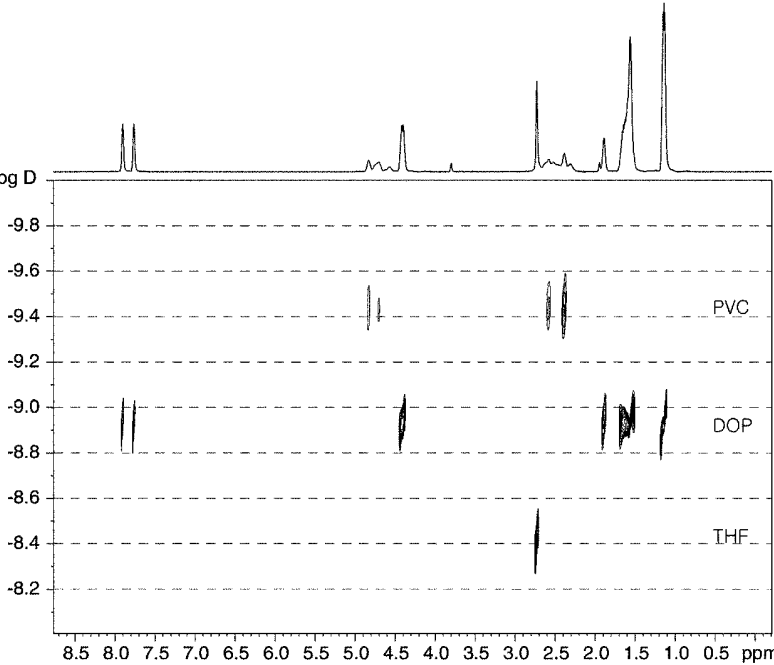

(b)

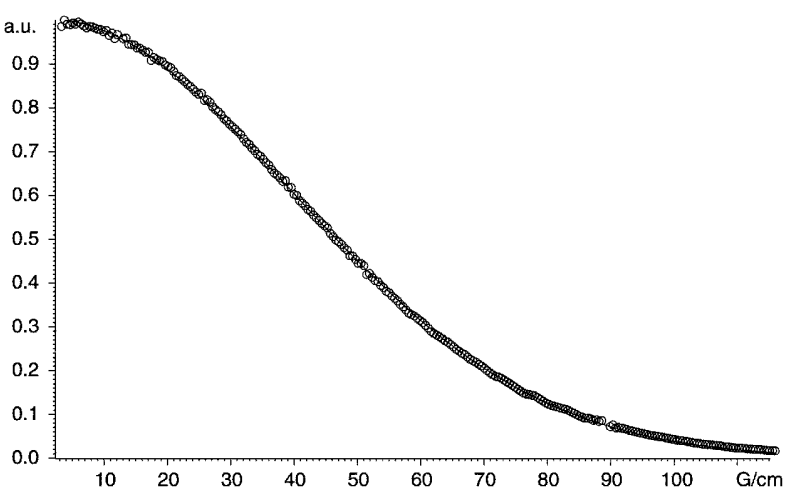

Fignre 1. (a) 'II DOSY spectrum of the eraser sample showing resolution of the individual components - PVC, DOP, and THF alongs the diffusion dimension and (b) diffusion decay curve for the DOP methyl proton peak $(-\cdots 1.1 \mathrm{ppm})$ by varying the sradient strength

signals of polymer additives can be identified from the polymer signals by DOSY technique without physical separation procedures. The resultant diffusion coefficients were $4.0 \times 10^{-116}, 1.3 \times 10^{-9}$, and $4.1 \times 10^{-8} \mathrm{~m}^{7} \mathrm{~s}^{-1}$ for the PVC, DOP, and THF siglals, respectively. Because exact measurement of the diffusion coefficients is not the purpose of this experiment, the values shown in all Figures must be treated relatively.

We have next carricd out the 2D-DOSY experiments on the graft copolymer and a mixture of PVC and EVA with composition of $45: 55 \mathrm{wt} \%$. Because two polymers. PVC and FVA. have diflerent molecular weights and hydrodynamic radii, the .VMR resonances in the DOSY spectrum can be identified by careful inspection of the peaks which aligned with a particular diffusion coeflicient in the contour plot. The diffusion coefficient of the PVC was found to be smaller than that of the EVA by $-40 \%$ as shown in Figure 2(a), and the difference could be large enough to distinguish two components in 2D-DOSY spectra. In the case of the graft copolymer, however, all the NMR signals (from the graft copolymer) should have same attenuation palterns resulting in a single diffusion coefficient since both units 
(a)

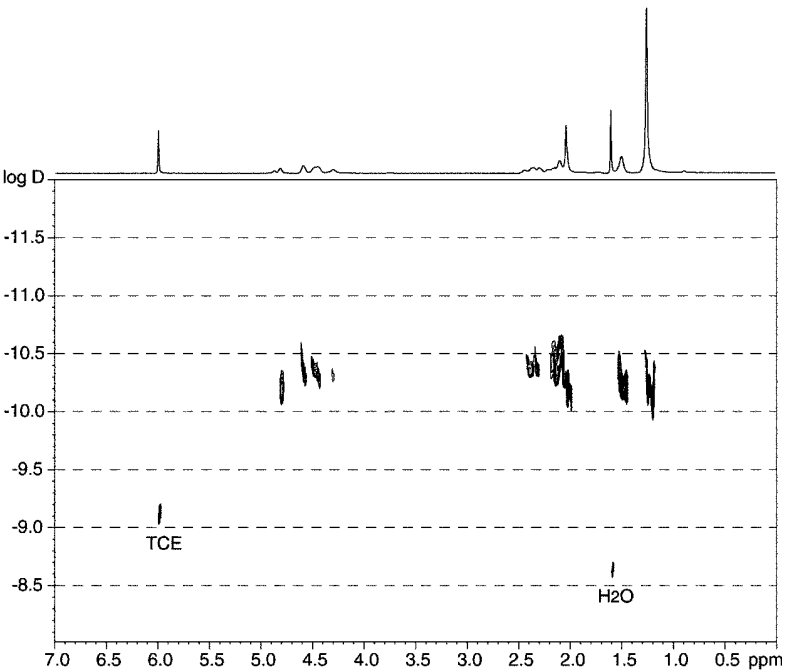

(b)

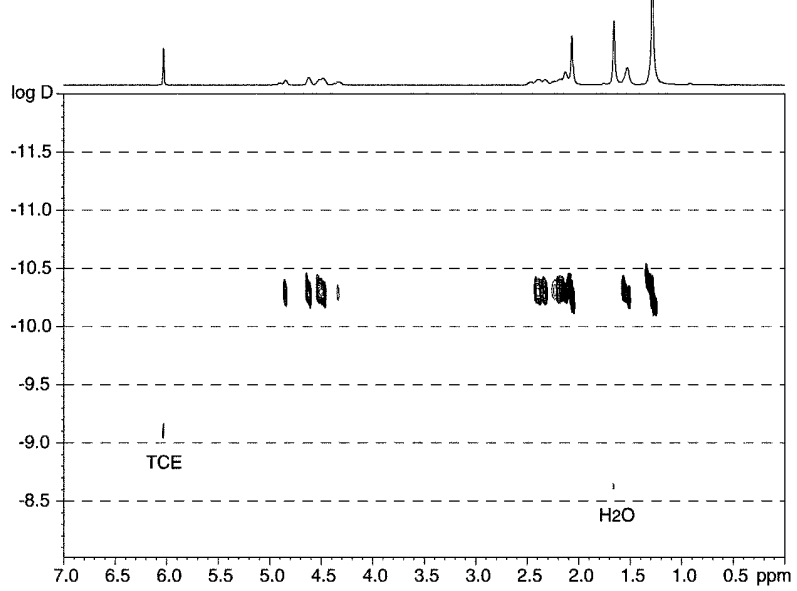

Figure 2. 'H DOSY spectrum of' (a) the polymer mixlure of PVC and EVA, and (b) the graft copolymer

(EVA and PVC) are present in a single molecule by grafting. Figure 2(b) shows that all N.MR peaks from the graft copolymer appeared parallel to the $x$-axis with the diffusion coefficient of $5.1 \times 10^{-11} \mathrm{~m}^{2} \mathrm{~s}^{-1}$. Although the 1D ${ }^{1} \mathrm{H} N \mathrm{M} R$ spectra of the polymer mixture and the graft copolymer drawn at the top of the corresponding 2D-DOSY contour plots are too similar to be distinguished each other, the different translational diffusion properties of the polymers ultimately showed up in different diffusion coefficients of each constituent polymer unit. Therefore well resolved 2DDOSY spectra would permit the confirmation of the grafting of two polymer units. Additional DOSY corelations from the solvent (THF) and residual water contaminant can also be observed with very larger diffusion coefficients than those of the polymers.

In summary, we have demonstrated a new potenlial of the 2D-DOSY techniques for the analysis of grafting copolymers distinguished from the polymer mixture of the corresponding polymer units having an almost idenlical 'H NMR spectrum. The DOSY .VMR technique can also be applied to examine other related copolymer systems of important industrial applications such as block-copolymers with long repeating units in the same manner.

Acknowledgements. This rescarch was supported by the Chung-Ang Liniversity Research Grants in 2004.

\section{References}

1. Johnson, C. S. Prog. Nuct. Magn. Resom. Siketrosc: 1999, 34, 20.3 .

2. Morris, M.: Johnson, C. S. J. Am. (hem. Soc: 1992, /14. 3139.

3. Cnoves, P.: Rasmussen, M. (): Molero, M. D: Samain, E.; Canada, F. I.; Driguez, II; Jimenez-Barbero, J. Clycobiology 2004, 14,451

4. Stchedroff, M. J ; Kenwriglth, A. M: Moris, G A.; Vilsson, M.; Harris, R. K. Phys (hom. (hem. Phws. 2004, 6, 3221

5. Vilsson, M.; Duarte, I. F.; Almeida, C.: Delgadil]o, I: Goodfellow, B. J.; Gil, A. M1.: Morris, G A. f. Agr. Food ( 'h'm. 2004, 52, 3736

6. Chen, A; Wu, D.; Johnson, C. S. J. Whes. (hem. 1995, 99, 828.

7. Price, K. Г.: L ucas, I. H.; I arive, C. K. Anal Bional. ( hem $20104,378,1405$.

8. Zhao, T: Beckham, II. W. Macromolecules 2003, 36, 9859

9. Kapur, C S : Findeisen, M ; Berger, S. Fic/ $2000,79,1347$.

10. Jerschow, A: Müller, ㅅ. Macromolecules 1998, 31, 6573.

11. Kin, H. U.: Lim, K. H. Bull. Kortem (hem. Sox. 2004, 25, 382

12. Barjat, H: Morris, G A. Swanson, A. G ./. Mensm. Resm. 1998, I3I, 131 .

13. Viel, S; Mantina, I.: Segre, A. Fetrahodron lett. 2002, 43, 2515.

14. Martions de Carvalho, E.; Velloso, M. II. R: Tinoco, L. W. Figueroa-Villar, J. D. J. Magn. Reson. 2003, 16t, 197.

15. Diaz, M. D.; Berger, S. Carbolmxh: Res. 2000, 329, l.

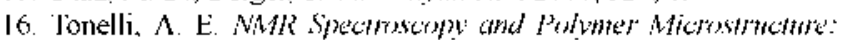
The ('omfonmational ("omection, VCH l'ublishers: Deerfield Beach, 1989.

17. Rittig, F.; Karger, J ; Papadakis, C. M.; Fleischer, G; Stepanek. P.: Almdal, K. Thys. (hem. ( hem. l'hys. 1999, 1, 3923.

18. Jayawickrama, D. A; Larive, C. K: McCord, E. F.: Roe, D. C. Magn. Resm. (Them. 1998, 36, 755.

19. Wu, D; Johnson, C. S. I. Magn. Keson. A 1995, //5, 260. 